\title{
Older Adults Had Similar Survival Rates Compared to Their Younger Counterparts Following Cardiopulmonary Resuscitation
}

\author{
Ali Al Ahmar'1, Jamal El Eid², Zouheir El Imad3,4, Husam F. Ghusn 3,4* \\ ${ }^{1}$ Ain Wazein Medical Village, Chouf, Lebanon \\ ${ }^{2}$ American University of Beirut, Beirut, Lebanon \\ ${ }^{3}$ Lebanese University, Beirut, Lebanon \\ ${ }^{4}$ Geriatrics and Extended Care Department, Ain Wazein Medical Village, Chouf, Lebanon \\ Email: *Husam.ghusn@awmedicalvillage.org
}

How to cite this paper: Al Ahmar, A., El Eid, J., El Imad, Z. and Ghusn, H.F. (2017) Older Adults Had Similar Survival Rates Compared to Their Younger Counterparts Following Cardiopulmonary Resuscitation. Advances in Aging Research, 6, 73-82. https://doi.org/10.4236/aar.2017.65008

Received: May 27, 2017

Accepted: September 25, 2017

Published: September 28, 2017

Copyright (c) 2017 by authors and Scientific Research Publishing Inc. This work is licensed under the Creative Commons Attribution International License (CC BY 4.0).

http://creativecommons.org/licenses/by/4.0/

\begin{abstract}
Background: Several factors affect the outcome of cardiopulmonary resuscitation (CPR) following in hospital cardiac arrests, including presence of comorbidities, arrest characteristics, and resuscitation efforts. We sought to determine the outcome of CPR provided to elders suffering from in-hospital cardiopulmonary arrest and to compare it to the survival of their younger counterparts in a tertiary care center in Lebanon. Methods: Retrospective chart review of all patients suffering from cardiac arrests who received CPR during a one year period in a tertiary care center located in a rural area. Results: A total of 98 cardiac arrests were identified who received CPR according to advance cardiac life support protocols (ACLS). Initial return of spontaneous circulation was higher among younger subjects but the difference was not statistically significant ( $52.6 \%$ vs $34.2 \%, \mathrm{p}=0.136)$. Survival to discharge was low but slightly higher in the younger subgroup, yet the difference was not statistically significant ( $5 \%$ vs $3 \%, p=0.535$ ). Conclusions: Physicians need to be aware of the outcome of CPR in the hospitals they practice in. They can educate their patients about CPR outcome. Such education may help patients and their next of kin make informed decisions jointly with their physician regarding resuscitation.
\end{abstract}

\section{Keywords \\ Cardiopulmonary Resuscitation, Elderly, Inpatient}

\section{Introduction}

In-hospital cardiac arrests are commonly associated with significant morbidity 
and mortality. In the United States, every year about 200,000 patients experience a cardiac arrest while they are hospitalized [1]. Around 2.73 cardiac arrests occur per 1000 admissions and the incidence is on the rise [2] [3]. Mortality remains high despite improvements in survival and neurological outcomes [4]. Initial return of spontaneous circulation (ROSC) can be seen in about $50 \%$ of the patients [5]. Those initial survivors suffer from significant morbidity due to the underlying comorbidities that led to the cardiac arrest, injury to organs due to the transient hypoperfusion and hypoxia during the arrest and reperfusion damage [6], requiring care in intensive care settings. Survival to discharge is variable (9\% 20\%) [3] [7] [8] [9] [10]. However, a significant proportion of survivors (25\%) suffer permanent neurological disability on discharge.

Survival predictors of in-hospital cardiac arrest are many. Increasing age has been associated with worse survival in some studies [10] [11] [12], but others did not demonstrate a significant association between age and arrest survival [13] [14]. Among elders, gender has not been shown to impact outcome [15]. Comorbidities highly influence cardiopulmonary resuscitation (CPR) outcome. Several studies demonstrated that the presence of sepsis, renal failure, malignancy, stroke, hypotension, and dependence in activities of daily living (ADLs) requiring a homebound lifestyle to be associated with poor survival following in-hospital cardiac arrest [13] [16] [17] [18]. In addition use of mechanical ventilation, vasopressors in critically ill patients are indicators of low likelihood of survival following arrests [13] [17] [18]. On the other hand, acute myocardial infarction and the presence of shockable rhythms such as ventricular tachycardia (VT) or ventricular fibrillation (VF) have been associated with good outcome [19], four to five times higher than patient with asystole or pulseless electrical activity (PEA).

Prompt resuscitation, receiving CPR within the first minute, and defibrillator shocks within 2 minutes if the patient is suffering from VT or VF are important in securing a better CPR outcome [20] [21]. However, prolonged resuscitation more than 15 minutes is a predictor of poor outcome due to the increased likelihood of organ damage especially the brain [18]. Being in a monitored area such as intensive care unit may indicate sicker patients but the promptness of initiating CPR has positive impact on outcome.

The purpose of this study was to determine the survival and outcome of CPR provided to elders suffering from an in-hospital cardiopulmonary arrest and to compare it to the survival of their younger counterparts in a tertiary care center in Lebanon.

\section{Methods}

The study is a retrospective chart review that involved all patients who suffered from inpatient cardiopulmonary arrest in a tertiary care center located in a rural area in Lebanon serving around 400,000 inhabitants. All inpatient cardiac arrests during the period Jan. 2010 to Dec. 2011 were identified using ICD10 codes for cardiac arrest and resuscitation. A list of all such patients was obtained from the computerized medical record system utilized by the hospital. Cardiopulmonary 
arrest and resuscitation were verified by one of the investigators through reviewing the CPR sheet that is filled during every arrest by the resuscitation team. Any patient in whom CPR could not be verified was excluded from the study. Demographic characteristics, medical diagnoses, characteristics of the arrest, resuscitation effort, survival post arrest, survival to discharge and functional status on discharge were retrieved from medical and nursing notes in the computerized medical record.

Resuscitation team

The unit registered nurse or any other staff report to the telephonist at the switch board any patient who suffers from respiratory or cardiac arrest, and initiates basic life support. The telephonist immediately notifies the code team of such occurrence. Team members report to the designated unit, assess the patient and continue resuscitation effort according to advanced cardiac life support (ACLS) guidelines. The resuscitation team is comprised of the intensive care unit (ICU) resident, a cardiologist, a nursing supervisor in addition to the unit resident and unit nursing staff. Standardized resuscitation equipment, defibrillators and emergency crash carts are present on all units of the hospital. Following the completion of the resuscitation effort, a standardized resuscitation form is completed by the ICU resident and is kept in the medical record.

\section{Results}

\section{Demographic characteristics:}

A total of 98 cardiopulmonary arrests occurred during this time period with a greater proportion of the cardiac arrests occurring among those above the age of 65 ( $1.12 \%$ vs $0.16 \%$ among those less than 65 yrs). The mean age of the younger patients suffering from cardiopulmonary arrest was $49.8 \pm 17.5$ yrs compared to $79.9 \pm 4.0$ yrs among the elderly $(\mathrm{p}<0.001)$. Coronary artery disease was much more common among the elderly; $39 \%$ compared to $10 \%$ among their younger counterparts, $\mathrm{p}=0.019$. Similarly, hypertension was more common among elders $(56 \%$ vs $26 \% \mathrm{p}=0.021$, Table 1$)$. Dementia was reported among $5 \%$ of the older subgroup whereas none of the younger subjects suffered from dementia. More elders suffered from pneumonia $63 \%$ compared to $33 \%$ of the younger subgroup, $\mathrm{p}=0.023$. Psychiatric disorders were more prevalent in the younger subgroup $(21 \%$ vs $5 \%, p=0.027)$. Otherwise the frequency of significant illnesses and major system dysfunction was similar among the two groups as outlined in Table 1. Functional status was comparable among the two subgroups (Table 2). Both groups were quite dependent in their ADLs with less than $20 \%$ of them able to eat independently, and less than $8 \%$ able to dress without help or to ambulate independently. Prior to their arrest, elders were receiving care in intensive care for a slightly longer period of time than their younger counterparts (2.79 vs 1.93 days, $\mathrm{p}=0.485$ ).

\section{Arrest characteristics:}

Most of the arrests were classified of cardiac origin, 90\% in each group. Asystole 
Table 1. Demographic and clinical characteristics of study group.

\begin{tabular}{cccc}
\hline Group & Group 1 (age $<65)$ & Group 2 (age $\geq 65)$ & P value \\
\hline Age (yrs) & $49.7 \pm 17.5$ & $79.9 \pm 4.0$ & $<0.001$ \\
Gender & & & \\
Male & $10(53)$ & $46(58)$ & 0.24 \\
Female & $9(47)$ & $33(42)$ & \\
Medical illnesses & & & \\
Coronary artery disease & $2(10)$ & $27(39)$ & 0.019 \\
Congestive heart failure & $3(17)$ & $26(39)$ & 0.072 \\
Chronic obstructive lung disease & $6(32)$ & $14(18)$ & 0.208 \\
Malignancy & $4(21)$ & $14(19)$ & 0.854 \\
Anemia & $8(44)$ & $51(65)$ & 0.1 \\
Chronic kidney disease & $7(44)$ & $27(42)$ & 0.872 \\
Hypertension & $5(26)$ & $43(56)$ & 0.021 \\
Stroke & $2(11)$ & $10(13)$ & 0.771 \\
Dementia & $0(0)$ & $5(28)$ & 0.013 \\
Diabetes mellitus & $5(28)$ & $26(35)$ & 0.578 \\
Liver cirrhosis & $2(11)$ & $2(3)$ & 0.121 \\
\hline
\end{tabular}

Legend for Table 1: Medical illnesses among the two groups.

Table 2. Functional status prior to arrest.

\begin{tabular}{cccc}
\hline Group & Group 1 (age $<65)$ & Group 2 (age $\geq 65)$ & P value \\
N $(\%)$ & N (\%) & \\
Eating & & & \\
Dependent & $7(47)$ & $27(40)$ & \\
Needs assistance & $5(33)$ & $28(42)$ & \\
Independent & $3(20)$ & $12(18)$ & 0.595 \\
Dressing & & & \\
Dependent & $8(62)$ & $30(49)$ & \\
Needs assistance & $4(30)$ & $28(46)$ & 0.323 \\
Independent & $1(8)$ & $3(5)$ & \\
Grooming & & $30(46)$ & \\
Dependent & $10(67)$ & $31(48)$ & \\
Needs assistance & $4(27)$ & $4(6)$ & \\
Independent & $1(7)$ & & \\
Walking & & $27(44)$ & \\
Dependent & $10(72)$ & $20(48)$ & \\
Needs assistance & $3(21)$ & $5(8)$ & \\
Independent & $1(7)$ & & \\
Getting in and out of bed & $10(72)$ & $29(44)$ & \\
Dependent & $3(21)$ & & \\
Needs assistance & $1(7)$ & & \\
Independent & & & \\
\hline
\end{tabular}

Legend for Table 2: Functional status by group is outlined. Both groups were dependent in their activities of daily living and no statistical difference was noted between the groups. 
Table 3. Resuscitation effort by group.

\begin{tabular}{cccc}
\hline Effort & Group 1 (age $<65)$ & Group 2 (age $\geq 65)$ & P value \\
\hline Time to intubation (min) & $5.33 \pm 3.20$ & $4.45 \pm 4.02$ & 0.818 \\
Number of shocks & $0.88 \pm 1.78$ & $0.55 \pm 1.37$ & 0.432 \\
Duration of resuscitation (min) & $25.17 \pm 11.05$ & $28.88 \pm 15.67$ & 0.438 \\
Adrenaline (mg) & $4.71 \pm 4.12$ & $6.06 \pm 4.16$ & 0.246 \\
Atropine (mg) & $1.99 \pm 1.64$ & $2.47 \pm 2.74$ & 0.504 \\
Amiodarone (mg) & $9.38 \pm 37.5$ & $14.06 \pm 63.91$ & 0.780 \\
Lidocaine (mg) & $0.00 \pm 0.00$ & $1.25 \pm 9.68$ & 0.620 \\
Sodium bicarbonate (mEq) & $33.33 \pm 55.89$ & $35.87 \pm 50.18$ & 0.864 \\
Clacium gluconate (amp) & $0.13 \pm 0.34$ & $0.13 \pm 0.38$ & 1.00 \\
\hline
\end{tabular}

Legend for Table 3: Resuscitation efforts were similar among the two groups.

was the predominant initial rhythm among the two subgroups, and it was much more common among the elderly (68\% vs $57 \%$ ), as opposed to VF which was more common among the younger subgroup ( $14 \%$ vs $2 \%) ; p=0.019$. Almost all of the arrests were witnessed, being in the hospital, with a similar proportion among the two subgroups.

Effort characteristics:

Resuscitation efforts were similar among the two subgroups in terms of time to intubation, number of shocks, duration of resuscitation and utilization of mediations (Table 3)

Survival:

Initial return of spontaneous circulation was higher among younger subjects but the difference was not statistically significant $(52.6 \%$ vs $34.2 \%, \mathrm{p}=0.136)$. Following attainment of initial rhythm, elders stayed in ICU for a slightly longer period of time and their hospital length of stay was longer (7.76 \pm 10.2 vs $3.58 \pm$ 3.37 days), but the differences were not statistically significant. Survival to discharge was low and was slightly higher in the younger subgroup but the difference was again not significant ( $5 \%$ vs $3 \%, p=0.535$ ). Survival to discharge did not correlate with the status of the arrest, whether witnessed or not $(p=0.847)$, or with the initial rhythm $(\mathrm{p}=0.074)$, perhaps due to the small number of survivors.

Functional status on discharge:

Out of the surviving patients to discharge, functional status was mentioned by the attending physician for only one patient who was dependent in his ADLs on discharge. One of the survivors was discharged home and two were transferred to another hospital.

\section{Discussion}

Cardiopulmonary resuscitation rates are increasing in hospital settings over the years [3], with the default policy advocating resuscitation to those who suffer from a cardio-pulmonary arrest unless a do not resuscitate order has been placed 
in the chart of the patient. Survival to hospital discharge following CPR for in-hospital cardiac arrest has variable success rates ranging from $9 \%-36.4 \%$ depending on the patient population studied [2]-[18], with one year survival rates following successful discharge as high as $60 \%$ and 3 year survival rate similar to heart failure patients [21]. The variations in survival rate relate to differences in patient population studied, arrest and effort characteristics, selection for CPR support and post arrest care. Advancing age has been reported to be associated with poor CPR outcome by some investigators [7]. However, the short and long term neurologic outcome of successfully resuscitated elders is dependent on arrest characteristic rather than age [22]. It is rather the presence of much comorbidity which determines successful resuscitation to discharge [23] [24]. This may explain the relatively lower survival rate to discharge observed among our study group compared to that published in the literature.

A primary diagnosis of acute myocardial infarction has been associated with increased survival rate to discharge [19], whereas the presence of cancer, metastatic disease, sepsis or pneumonia has been associated with poor outcome. Our patients were reported to have suffered from cardiac arrest in the majority of the cases, a higher proportion than that reported in the literature [25], yet only $30 \%$ suffered from acute myocardial infarction indicating that the labeling of cardiac arrest is probably overestimated or that it was a mixed respiratory cardiac arrest.

Shockable rhythms such as VT and VF have been associated with higher survival to discharge. Although older adults are reported to have a low rate of shockable rhythms, with PEA as the most common primary arrhythmia [26], the rate of shockable rhythms in our study was much lower than that reported in the literature which may help explain the lower survival rates to discharge. This may reflect the higher rate of comorbid illnesses or a higher desire on the part of non-salvageable patients to receive resuscitation especially that Do Not Resuscitate orders are not yet commonly used in Lebanon.

Return of spontaneous circulation was achieved in $43.2 \%$ in the overall group which is a roughly similar rate to that published in the literature [9], but the lower survival rate to discharge could be explained by a high burden of illness, reflected in a high rate of functional dependence prior to the arrest and the tendency for some families and their physicians to forgo resuscitation if a second arrest was sustained consistent with studies that show a significantly lower likelihood of survival to discharge following multiple CPRs [24].

Several decision tools can be used to help select the best candidates for CPR. Pre arrest criteria such as advanced age above 70 years, high serum creatinine, and presence of metastatic cancer have been among the suggested variables to be used in predicting CPR outcomes. Other decision aids utilize single criteria such as witnessed arrest, VT, VF as initial rhythms [27]. APACHE II scores [28], pre arrest morbidity index (PAM index) [18], prognosis after resuscitation (PAR) index utilize several pre arrest characteristics to predict the likelihood of survival with higher scores predicting worse outcomes [19] [29]. Both scores have poor 
sensitivity and high specificity for correctly identifying non-survivors and lacked the ability to discriminate among survivors and non-survivors [19] [29]. Combining PAM, modified PAM and PAR identified $42 \%$ of the unsuccessful CPR attempts indicating the need to refine these tools some more [30]. Physicians can utilize such tools to help them predict patients who could benefit from CPR and can utilize such predictive tools in the process of educating patients about CPR Outcome.

Resuscitation effort was carried accordingly to ACLS guidelines, but this activity avails itself for improvement in terms of its timeliness and concordance according to guidelines. In fact, Abella et al. found that the quality of multiple parameters of CPR in several university hospitals and reported that it was inconsistent and often did not meet published guideline recommendations even when performed by well-trained hospital staff [31].

Resuscitation is desired by many elderly, as many as $60 \%$ of elderly patients, particularly if they are functionally independent. In one study, $67 \%$ welcomed inquiry about their preferences and $78 \%$ wanted participation in decisions with about $43 \%$ wanting to be the sole decision-maker in this matter [32]. Most of the older patients would like to undergo CPR in case they suffer an in-hospital cardiac arrest despite knowledge about its poor outcome and believe that they should have the right to accept or deny treatment [33]. Despite poor knowledge about outcome of resuscitation, many patients would like to be resuscitated in case they suffered an in-hospital cardiac arrest and believe that they should have the right to accept or refuse treatment [33]. When older people are questioned about their resuscitation preferences, those who wanted CPR highlight their experiences of meaningful life or fulfillment of their life, interpersonal relationships with their loved ones and presumed outcome of CPR. Patients preferring CPR estimated their prognosis of CPR to be better than those preferring to forgo CPR. They justified their view that life is precious and worth living for and that maintaining life is a value of its own [33]. On the contrary, $48 \%$ of the participants preferring to forgo CPR justified their decision with "I have already gained old age and led a full life". Although less than $50 \%$ of the patients wished to discuss CPR in their current situation with their physician, they nevertheless wanted to participate in the discussion about end-of-life treatment.

A reasonable option for those electing to have CPR is to be able to decide to forgo or discontinue resuscitation if it is unlikely that they will recover with good neurologic function instead of being forced to make a decision to forgo CPR [34]. Patients who have unwitnessed arrest, an unshockable rhythm and no recovery of spontaneous circulation after 10 minutes of resuscitation are highly unlikely to benefit from further resuscitation and such effort could be halted [27]. Other scales such as the Resuscitation Predictor Scoring (RPS) could be used 15 min into a resuscitation attempt to predict survival to discharge. It is an acceptable point at which to first consider termination of CPR if there has been no return of spontaneous circulation [35]. Similarly, the Cardiac Arrest Survival 
Post Resuscitation In-hospital (CASPRI) score which includes several predictor variables such as age, initial cardiac arrest rhythm, defibrillation time, baseline neurological status, duration of resuscitation, mechanical ventilation, renal insufficiency, hepatic insufficiency, sepsis, malignancy, and hypotension could be utilized to predict the likelihood of survival to discharge. A CASPRI score 0 - 9 had a $70.7 \%$ mean probability of favorable neurological survival compared to patients with CASPRI score $\geq 28$ ) who had a $2.8 \%$ mean probability of favorable neurological survival [4].

\section{Conclusion}

In summary, well informed patients and their families have the right to receive or forgo CPR since each person has the right to determine what happens to his body and soul. Physicians have the hard task of educating patients and their families about CPR and its outcome based on studies addressing patient populations of similar characteristics. They need to assess the knowledge of patients about CPR outcomes, to educate them, to discuss such issues and plan in advance with patients and their families what to do in the event that cardiopulmonary arrest occurs. Such discussions will emphasize the principle of patient autonomy and will result in selection of good candidates for CPR who will hopefully be discharged alive in good neurological function to continue with their life. Further research about best education models, utilization of advance directives in Lebanon, and how such strategies can enhance CPR outcome is needed.

\section{References}

[1] Merchant, R.M., Yang, L., Becker, L.B., et al. (2011) Incidence of Treated Cardiac Arrest in Hospitalized Patients in the United States. Critical Care Medicine; 39, 2401-2406. https://doi.org/10.1097/CCM.0b013e3182257459

[2] Ehlenbach, W.J., Barnato, A.E., Curtis, J.R., et al. (2009) Epidemiologic Study of In-Hospital Cardiopulmonary Resuscitation in the Elderly. New England Journal of Medicine, 361, 22-31. https://doi.org/10.1056/NEJMoa0810245

[3] Kazaure, H.S., Roman, S.A. and Sosa, J.A. (2013) Epidemiology and Outcomes of In-Hospital Cardiopulmonary Resuscitation in the United States, 2000-2009. Resuscitation, 8, 1255-1260. https://doi.org/10.1016/j.resuscitation.2013.02.021

[4] Girotra, S., Nallamothu, B.K., Spertus, J.A., Li, Y., Krumholz, H.M. and Chan, P.S. (2012) Trends in Survival after In-Hospital Cardiac Arrest. New England Journal of Medicine, 367, 1912-1920. https://doi.org/10.1056/NEJMoa1109148

[5] Nadkarni, V.M., Larkin, G.L., Peberdy, M.A., et al. (2006) First Documented Rhythm and Clinical Outcome from In-Hospital Cardiac Arrest among Children and Adults. JAMA, 295, 50-57. https://doi.org/10.1001/jama.295.1.50

[6] Peberdy, M.A., Ornato, J.P., Larkin, G.L., et al. (2008) Survival from In-Hospital Cardiac Arrest during Nights and Weekends. JAMA, 299, 785-792.

https://doi.org/10.1001/jama.299.7.785

[7] Cooper, S., Janghorbani, M. and Cooper, G. (2006) A Decade of In-Hospital Resuscitation: Outcomes and Prediction of Survival? Resuscitation, 68, 231-237.

https://doi.org/10.1016/j.resuscitation.2005.06.012 
[8] Varon, J. and Fromm Jr., R.E. (1996) In-Hospital Resuscitation among the Elderly: Substantial Survival to Hospital Discharge. American Journal of Emergency Medicine, 14, 130-132. https://doi.org/10.1016/S0735-6757(96)90118-7

[9] Peberdy, M.A., Kaye, W., Ornato, J.P., et al. (2003) Cardiopulmonary Resuscitation of Adults in the Hospital: A Report of 14720 Cardiac Arrests from the National Registry of Cardiopulmonary Resuscitation. Resuscitation, 58, 297-308. https://doi.org/10.1016/S0300-9572(03)00215-6

[10] Cooper, S. and Cade, J. (1997) Predicting Survival, In-Hospital Cardiac Arrests: Resuscitation Survival Variables and Training Effectiveness. Resuscitation, 35, 17-22. https://doi.org/10.1016/S0300-9572(97)00020-8

[11] Tunstall-Pedoe, H., Bailey, L., Chamberlain, D.A., Marsden, A.K., Ward, M.E. and Zideman, D.A. (1992) Survey of 3765 Cardiopulmonary Resuscitations in British Hospitals (The BRESUS Study): Methods and Overall Results. BMJ, 304, 1347-1351. https://doi.org/10.1136/bmj.304.6838.1347

[12] Skrifvars, M.B., Castren, M., Nurmi, J., Thoren, A.B., Aune, S. and Herlitz, J. (2007) Do Patient Characteristics or Factors at Resuscitation Influence Long-Term Outcome in Patients Surviving to Be Discharged Following in Hospital Cardiac Arrest? Journal of Internal Medicine, 262, 488-495. https://doi.org/10.1111/j.1365-2796.2007.01846.x

[13] Bedell, S.E., Delbanco, T.L., Cook, E.F. and Epstein, F.H. (1983) Survival after Cardiopulmonary Resuscitation in the Hospital. The New England Journal of Medicine, 309, 569-576. https://doi.org/10.1056/NEJM198309083091001

[14] Sandroni, C., Ferro, G., Santangelo, S., et al. (2004) In-Hospital Cardiac Arrest: Survival Depends Mainly on the Effectiveness of the Emergency Response. Resuscitation, 62, 291-297.

[15] Topjian, A.A., Localio, A.R., Berg, R.A., et al. (2010) Women of Child-Bearing Age Have Better in Hospital Cardiac Arrest Survival Outcomes than Do Equal-Aged Men. Critical Care Medicine, 38, 1254-1260. https://doi.org/10.1097/CCM.0b013e3181d8ca43

[16] Ballew, K.A., Philbrick, J.T., Caven, D.E. and Schorling, J.B. (1994) Predictors of Survival Following In-Hospital Cardiopulmonary Resuscitation. A Moving Target. Archives of Internal Medicine, 154, 2426-2432. https://doi.org/10.1001/archinte.1994.00420210060007

[17] Chan, P.S., Spertus, J.A., Krumholz, H.M., et al. (2012) A Validated Prediction Tool for Initial Survivors of In-Hospital Cardiac Arrest. Archives of Internal Medicine, 172, 947-953. https://doi.org/10.1001/archinternmed.2012.2050

[18] George, A.L., Folk, B.P., Crecelius, P.L. and Campbell, W.B. (1989) Pre-Arrest Morbidity and Other Correlates of Survival after In-Hospital Cardiopulmonary Arrest. American Journal of Medicine, 87, 28-34.

[19] Ebell, M.H. (1992) Prearrest Predictors of Survival Following In-Hospital Cardiopulmonary Resuscitation: A Meta-Analysis. The Journal of Family Practice, 34, 551-558.

[20] Herlitz, J., Bang, A., Aune, S., Ekstrom, L., Lundstrom, G. and Holmberg, S. (2001) Characteristics and Outcome among Patients Suffering In-Hospital Cardiac Arrest in Monitored and Non-Monitored Areas. Resuscitation, 48, 125-135.

[21] Chan, P.S., Nallamothu, B.K., Krumholz, H.M., Spertus, J.A., Li, Y., Hammill, B.G. and Curtis, L.H. (2013) Long-Term Outcomes in Elderly Survivors of In-Hospital Cardiac Arrest. The New England Journal of Medicine, 368, 1019-1026.

https://doi.org/10.1056/NEJMoa1200657 
[22] Grimaldi, D., Dumas, F., Perier, M.C., Charpentier, J., Varenne, O., Zuber, B., Vivien, B., Pène, F., Mira, J.P., Empana, J.P. and Cariou, A. (2014) Short- and Long-Term Outcome in Elderly Patients after Out-of-Hospital Cardiac Arrest: A Cohort Study. Critical Care Medicine, 42, 2350-2357. https://doi.org/10.1097/CCM.0000000000000512

[23] Tortolani, A.J., Risucci, D.A., Rosati, R.J. and Dixon, R. (1990) In-Hospital Cardiopulmonary Resuscitation: Patient, Arrest and Resuscitation Factors Associated with Survival. Resuscitation, 20, 115-128.

[24] Menon, P.R., Ehlenbach, W.J., Ford, D.W. and Stapleton, R.D. (2014) Multiple In-Hospital Resuscitation Efforts in the Elderly. Critical Care Medicine, 42, 108-117. https://doi.org/10.1097/CCM.0b013e31829eb937

[25] Wallmuller, C., Giora Meron, I., Kurkciyan, I., Schober, A., Stratil, P. and Sterz, F. (2012) Causes of In-Hospital Cardiac Arrest and Influence on Outcome. Resuscitation, 83, 1206-1211.

[26] Elshove-Bolka, J., Guttormsena, A.B. and Austlid, I. (2007) In-Hospital Resuscitation of the Elderly: Characteristics and Outcome. Resuscitation, 74, 372-376.

[27] Walraven, C.V., Forster, A.A.J., Parish, D.C., Dane, F.C., Chandra, K.M.D., Durham, M.D., Whaley, C. and Stiell, I. (2001) Validation of a Clinical Decision Aid to Discontinue In-Hospital Cardiac Arrest Resuscitation. JAMA, 285, 1602-1606. https://doi.org/10.1001/jama.285.12.1602

[28] Beer, Teasdale, T.A., Ghusn, H.F. and Taffet, G.E. (1994) Estimation of Severity of Illness with APACHE II: Age-Related Implications in Cardiac Arrest Outcomes Pre Arrest APACHE II Is a Severity-of-Illness Score Has Been Used to Predict CPR Outcome. Resuscitation, 27, 189-195.

[29] O’Keeffe, S. and Ebellb, M.H. (1994) Prediction of Failure to Survive Following In-Hospital Cardiopulmonary Resuscitation: Comparison of Two Predictive Instruments. Resuscitation, 28, 21-25.

[30] Bowker, L. and Stewart, K. (1999) Predicting Unsuccessful Cardiopulmonary Resuscitation (CPR): A Comparison of Three Morbidity Scores. Resuscitation, 40, 89-95.

[31] Abella, B.S., Alvarado, J.P., Myklebust, H., Edelson, D.P., Barry, A., O’Hearn, N., Vanden Hoek, T.L. and Becker, L.B. (2005) Quality of Cardiopulmonary Resuscitation during In-Hospital Cardiac Arrest. JAMA, 293, 305-310.

[32] Bruce, J.P., Roberts, H., Bowker, L. and Cooney, V. (1996) Resuscitating the Elderly: What Do the Patients Want? Journal of Medical Ethics, 22, 154-159. https://doi.org/10.1136/jme.22.3.154

[33] Chliara, D., Chalkias, A., Horopanitis, E., Papadimitriou, L. and Xanthos, T. (2013) Attitude of Elderly Patients towards Cardiopulmonary Resuscitation in Greece. Geriatrics \& Gerontology International, 14, 874-879.

[34] Holm, S. and Jørgensen, E.O. (2001) Ethical Issues in Cardiopulmonary Resuscitation. Resuscitation, 50, 135-139.

[35] Coopera, S. and Duncan, F. (2007) Reliability Testing and Update of the Resuscitation Predictor Scoring (RPS) Scale. Resuscitation, 74, 253-258. 
Submit or recommend next manuscript to SCIRP and we will provide best service for you:

Accepting pre-submission inquiries through Email, Facebook, LinkedIn, Twitter, etc. A wide selection of journals (inclusive of 9 subjects, more than 200 journals)

Providing 24-hour high-quality service

User-friendly online submission system

Fair and swift peer-review system

Efficient typesetting and proofreading procedure

Display of the result of downloads and visits, as well as the number of cited articles Maximum dissemination of your research work

Submit your manuscript at: http://papersubmission.scirp.org/

Or contact aar@scirp.org 